УДК 621.18:697.326

К ВОПРОСУ МОДЕРНИЗАЦИИ ГАЗООБОРУДОВАНИЯ КОММУНАЛЬНЫХ КОТЛОВ

\title{
ABOUT MODERNIZATION OF COMMUNAL BOILER GAS EQUIPMENT
}

\author{
С.Г. Прохоров, И.С. Назаров
}

Пензенский государственный университет архитектуры и строительства

г. Пенза, Российская Федерация

Sergey G. Prokhorov, Ilya S. Nazarov

\section{Penza State University of Architecture and Construction \\ Penza, Russian Federation \\ e-mail: tgv@pguas.ru}

\begin{abstract}
Аннотация. В последние годы наметилась тенденция по замене существующих горелок на коммунальных паровых и водогрейных котлах на современные отечественного и импортного производства. Это обусловлено тем, что «родные» горелки не обеспечивают настоящие требования по энергоэффективности, охране окружающей среды, автоматизации и надёжности работы котлов. В статье приводятся примеры модернизации газооборудования на основе информационного поиска и результаты режимно-наладочных испытаний котла ДКВР-6,5/13, переведённого на водогрейный режим работы, до и после модернизации.
\end{abstract}

Abstract. In recent years, there has been a tendency to replace existing burners on municipal steam and hot water boilers with modern domestic and imported ones. This is due to the fact that the «native» burner does not provide 
these requirements for energy efficiency, environmental protection, automation and reliability of boilers. The article provides examples of modernization of gas equipment on the basis of information retrieval and the results of regimeadjustment tests of the boiler DKVR-6,5/13, transferred to the hot water mode, before and after modernization.

Ключевые слова: коммунальные котлы, модернизация газооборудования

Key words: municipal boilers, modernization of gas equipment

Информационный поиск показал, что в последние годы наметилась тенденция по замене существующих горелок на коммунальных паровых и водогрейных котлах на современные отечественного и импортного производства. Это обусловлено тем, что «родные» горелки не обеспечивают настоящие требования по энергоэффективности, охране окружающей среды, автоматизации и надёжности работы котлов [1].

Характерной особенностью указанных котлов являются короткие топки. Поэтому установка длиннофакельных горелок может привести к прожиганию задней стенки котла, затягиванию факела в конвективные поверхности нагрева, увеличению уровня химнедожога, неравномерной тепловой нагрузке поверхностей в топке и т.д.

Серийные импортные горелки, как правило, являются длиннофакельными, так как разработаны применительно к наддувным жаротрубным котлам. Поэтому объективно требовалась их модернизация с целью установки на котлах с короткими топками, работающими под разрежением, при равномерном распределении факела по объёму.

Компания Weishaupt (Германия) совместно с Бийским котельным заводом разработала горелки (исполнение SF) с коротким факелом для всех типов котлов, изготавливаемых заводом [2]. Установка горелки G5 на 
котле E-1,0-0,9 приведена на рисунке 1, а установка горелок G9 на котле ДЕ-4 и G40 на котле ДКВР-6,5 показана на рисунках 2 и 3.

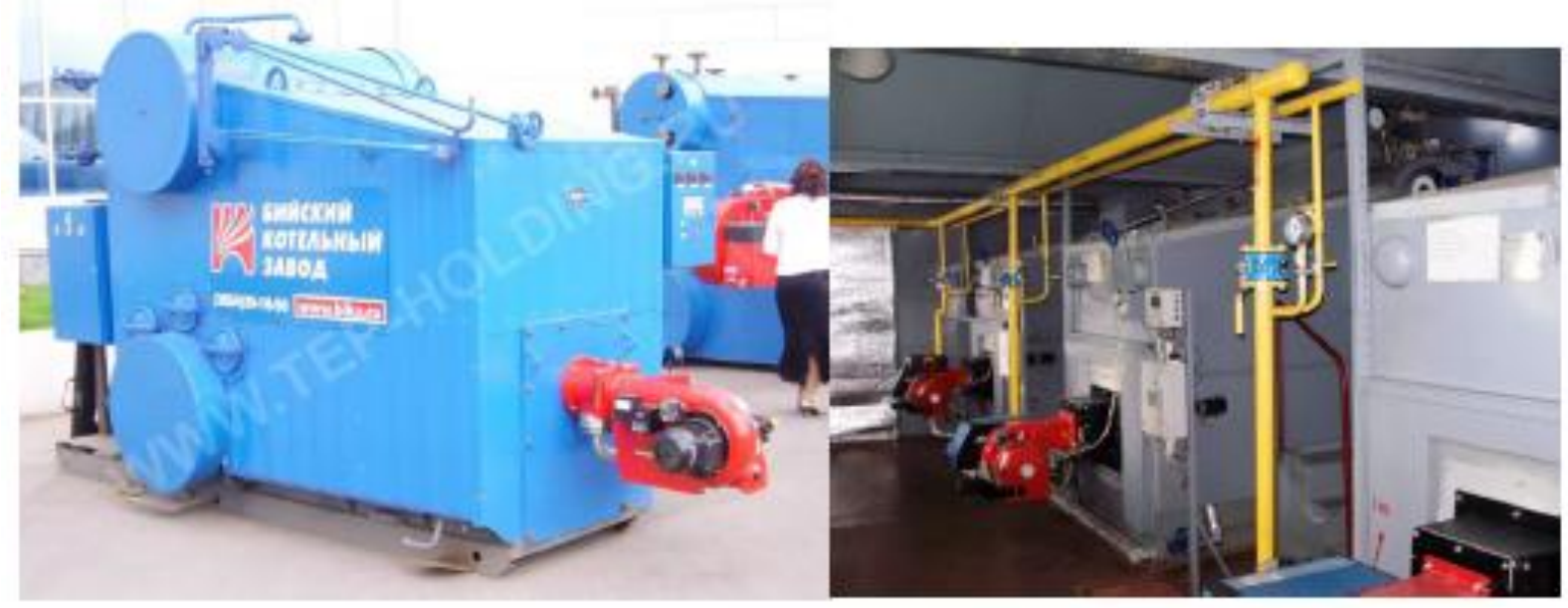

Рисунок 1. Установка горелки G5 на котле E-1,0-0,9

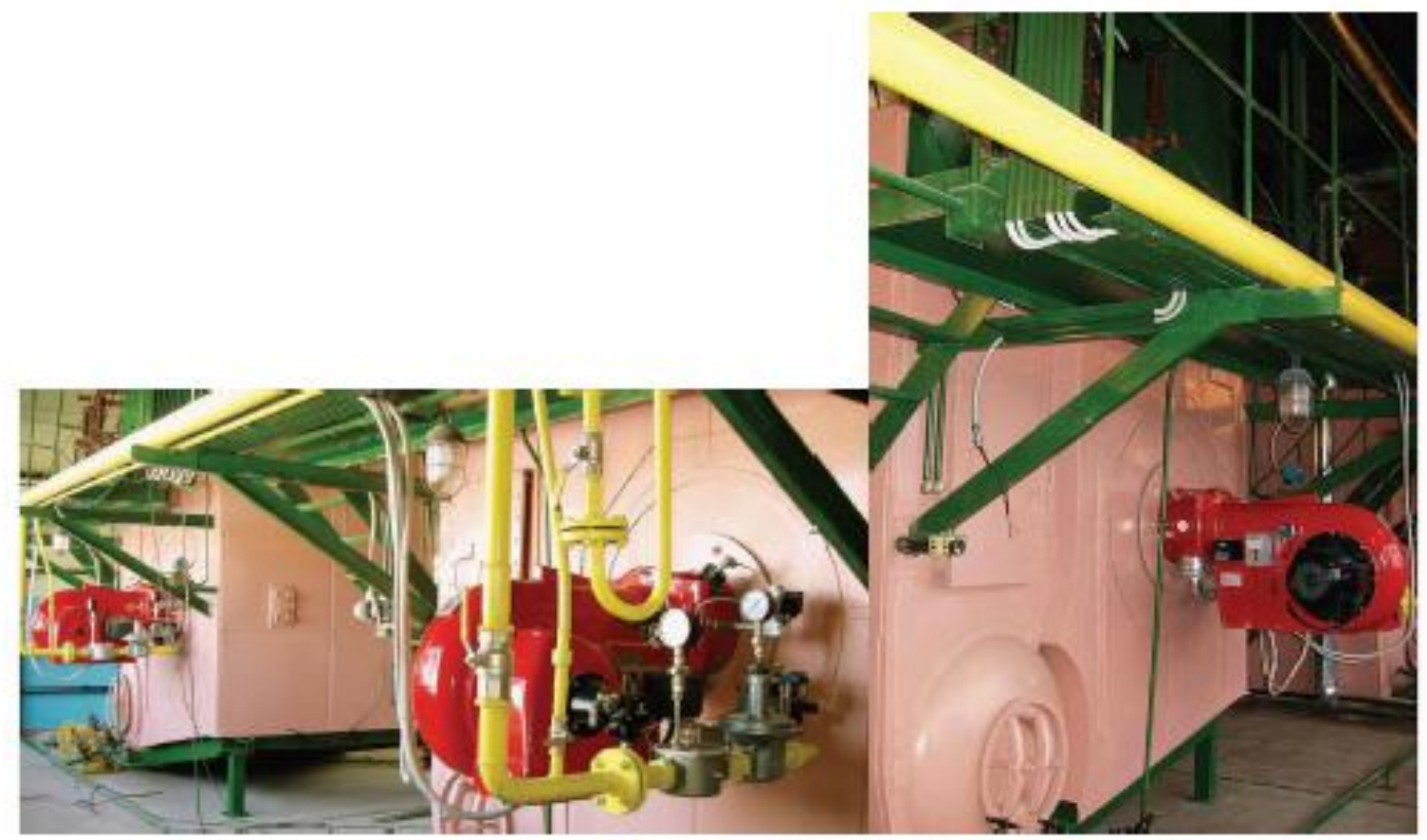

Рисунок 2. Установка горелки G9 на котле ДЕ-4 


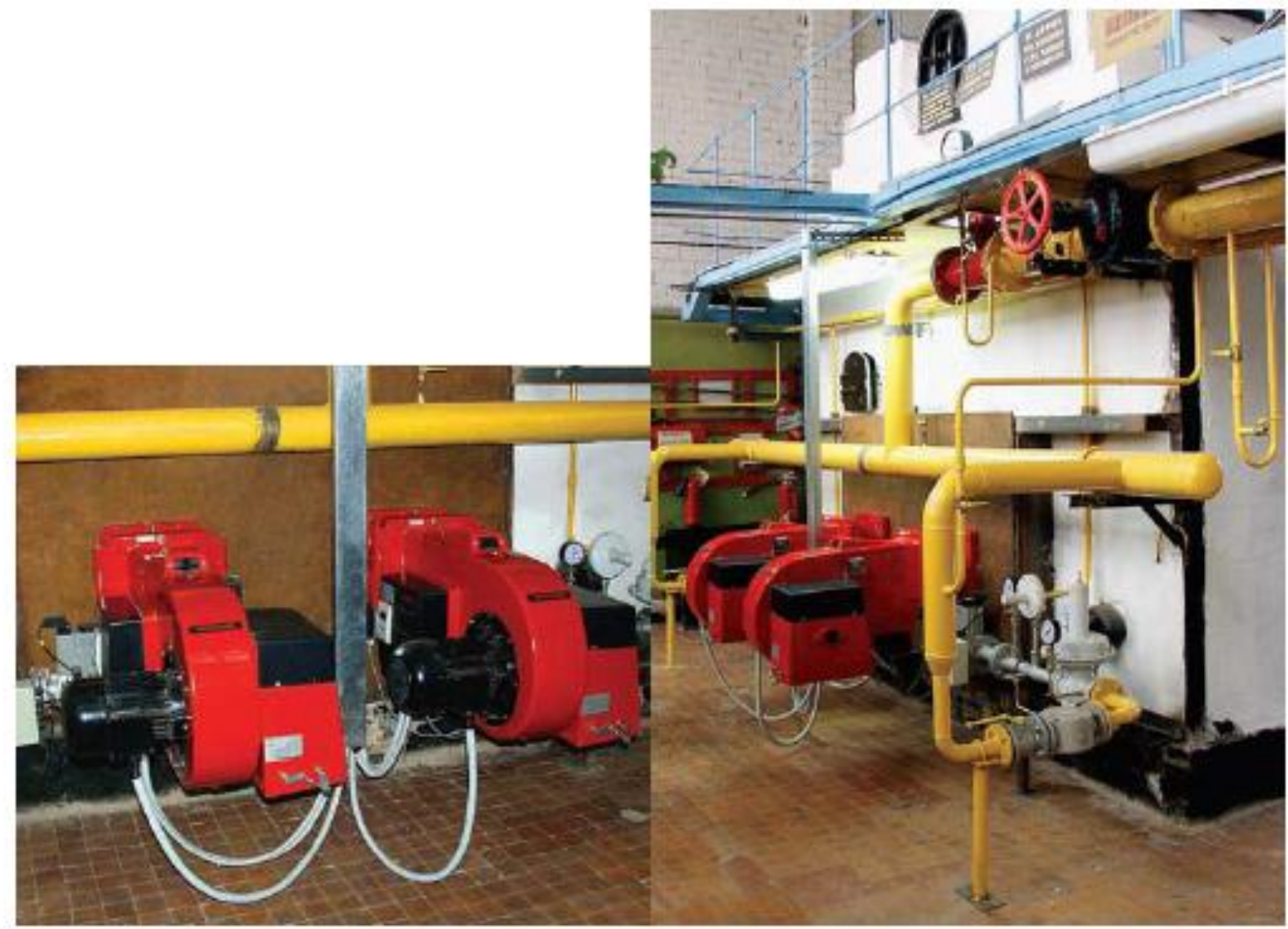

Рисунок 3. Установка горелки G40 на котле ДКВР-6,5

Применение короткофакельных горелок на котлах Бийского завода даёт [2]:

- увеличение КПД на 2,5-3,0 \% за счёт снижения потерь теплоты с уходящими газами и с химнедожогом;

- применение систем плавного частотного и кислородного регулирования;

- увеличение диапазона регулирования (в среднем $1: 7$ );

- равномерное распределение факела по всей камере сгорания котла;

- максимум теплового излучения в топке котла составляет 105-110\% от среднего, что существенно снижает требования к циркуляционному контуру котла;

- снижение содержания оксидов азота в продуктах сгорания в 1,5-2 раза, так как максимальная температура в «ядре» горения $1350-1480{ }^{\circ} \mathrm{C}$; 
- повышение уровня автоматизации за счёт применения систем микропроцессорного регулирования, поставки горелок со шкафами управления и безопасности котла, возможности передачи данных по цифровым каналам связи;

- удобство обслуживания и эксплуатации за счёт блочного исполнения горелок (в блок входят все элементы, необходимые для подготовки и подачи топлива в зону горения, приборы автоматического регулирования процессом горения и аварийной защиты).

Специалисты компании CIB UNIGAS также решали проблему адаптации своих горелок к котлам российского производства [3]. Отмечалось, что топки водотрубных котлов достаточно короткие для корректной работы горелок стандартного исполнения. Поэтому были разработаны короткофакельные горелки DRAGO, которые образуют широкое, короткое и равномерно распределённое по объёму топки пламя (рисунки 4 и 5).

Это обусловлено применением четырёх форсунок с целью формирования геометрии факела.

На котле устанавливается одна горелка, независимо от того сколько горелок стояло ранее. Выход на максимальную мощность горелки осуществляется постепенно, чтобы предотвратить напряжение на обмуровку котлов. В электрощите устанавливается автомат горения производства Siemens, на котором задаются пределы регулирования давления пара или температуры воды, если котёл работает в водогрейном режиме, а в котле устанавливается соответствующий датчик, посылающий сигнал на этот прибор. В результате горелка способна автоматически поддерживать заданные при пуско-наладочных работах настройки.

При установке горелки на отечественный котёл делается проект привязки горелки к котлу и к котельной автоматике. Работа горелки, имеющей свой вентилятор, должна быть скоординирована с работой 
дымососа. Применение горелок согласовано для большинства котлов российских производителей.

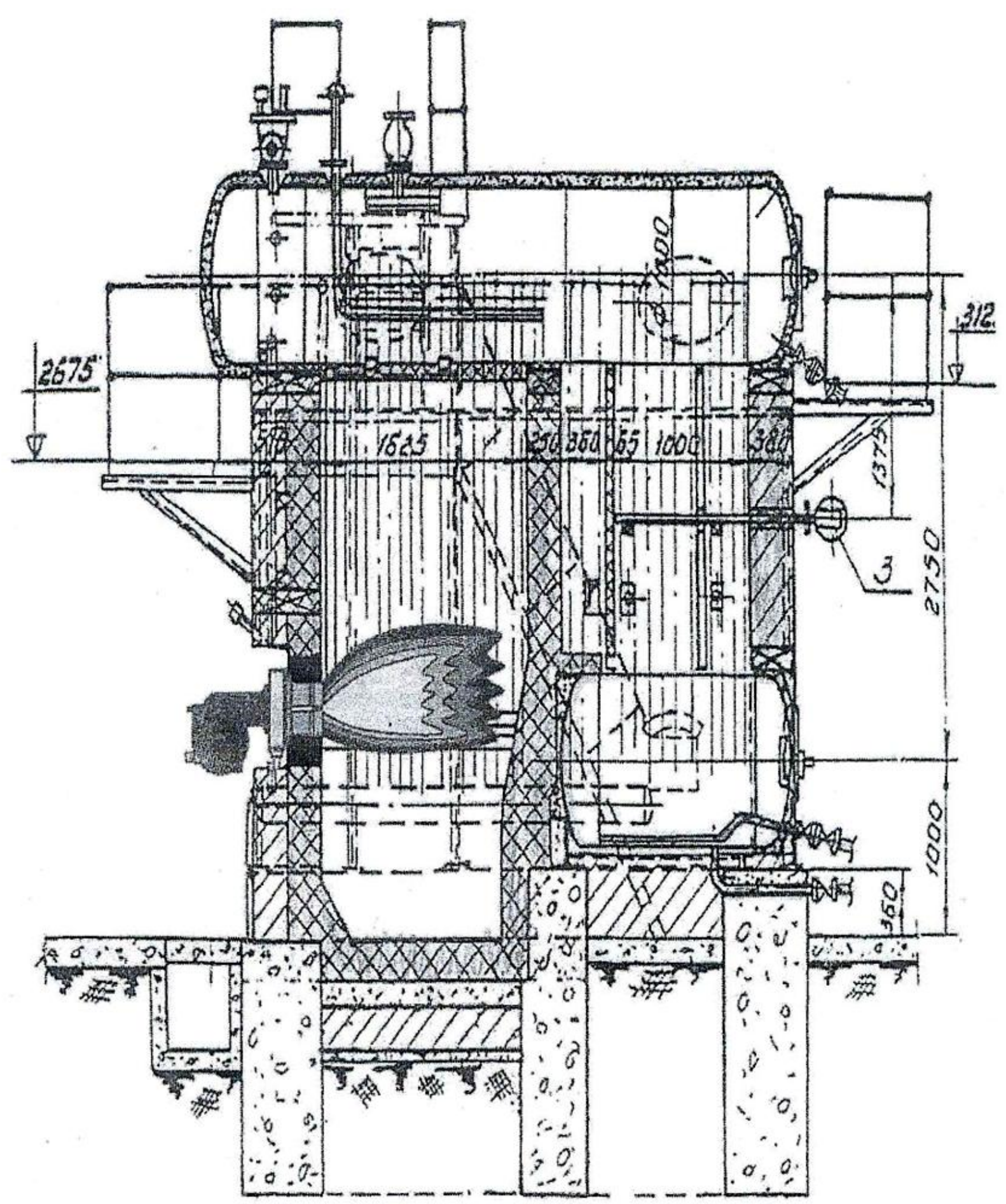

Рисунок 4. Схема установки короткофакельной горелки типа DRAGO на котле ДКВР 


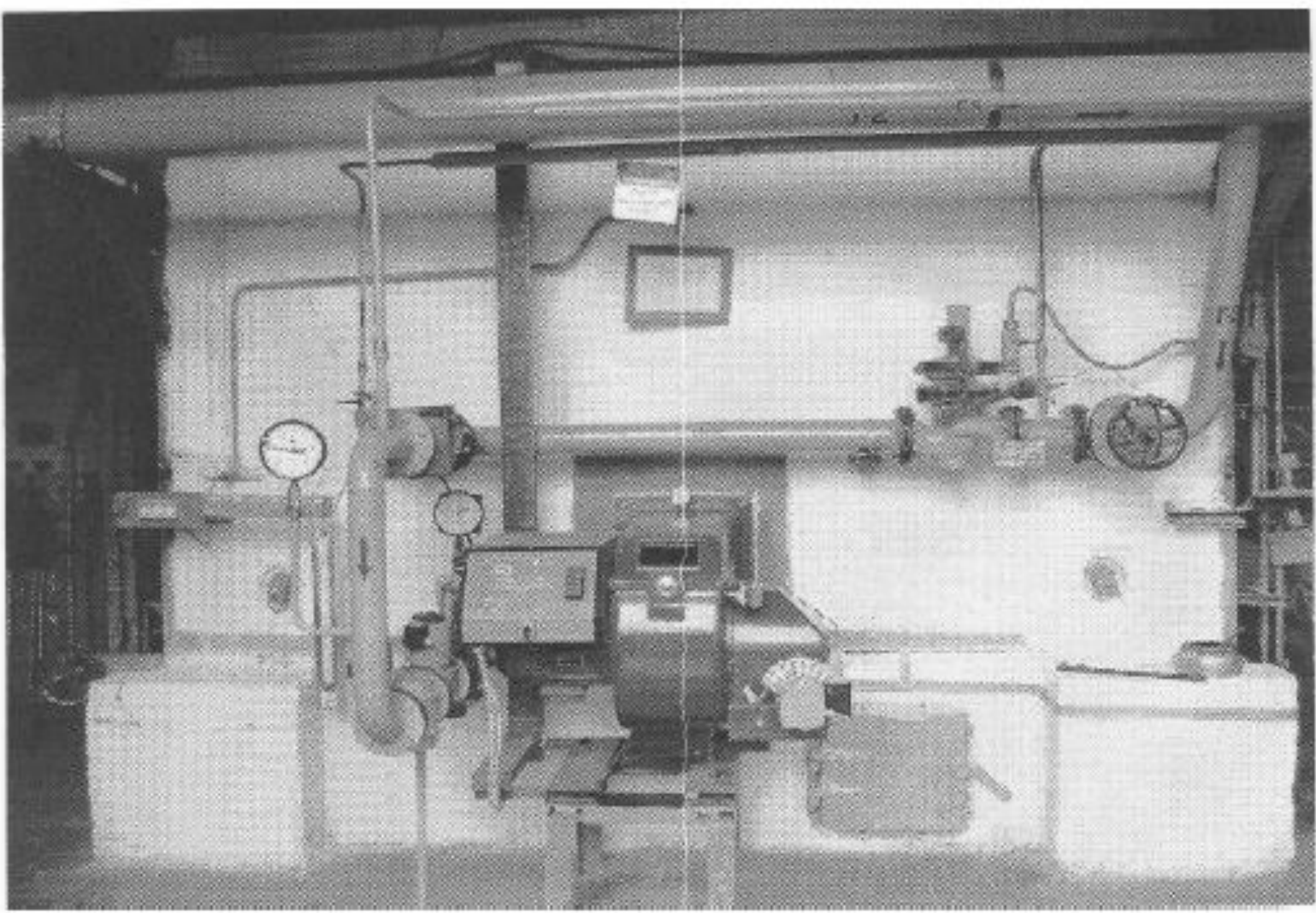

Рисунок 5. Установка горелки типа DRAGO на котле ДКВР-10

ООО «Энергодевелопмент» (г. Реутов Московской области) совместно с итальянской фирмой Industrial Burnes Solutions реализовала пилотный проект по переводу котла ДКВР-20-13 с мазута на газовое топливо [4]. Две горелки ГМГ были заменены горелками IBSR 6M с изменяемой геометрией факела и горелочной автоматикой фирмы Siemens (Германия).

При проведении работ выполнен ряд требований заказчика, в том числе сохранение двухгорелочной компоновки фронта котла. Фронтовой экран также не переделывался. Отметим, что проект переоснащения отечественных водотрубных котлов горелками IBS предусматривает и такой вариант - с компоновкой одной горелкой и переделкой фронта котла.

В результате:

- КПД котла увеличился до $93 \%$;

- содержание оксида углерода в продуктах сгорания снизилось до 3 ppm;

- содержание оксидов азота снизилось до 63 ppm (при номинальной нагрузке); 
- уровень автоматизации работы котла был повышен до максимально возможного;

- эксплуатационные расходы уменьшились приблизительно в 2,5 раза;

- срок окупаемости проекта 1,5-2 года.

ООО «Норд Крафт» (г. Санкт-Петербург) был выполнен проект реконструкции двух котлов ДЕ-16-14ГМ в котельной спиртзавода (г. Буинск, Республика Татарстан) [5]. Вместо горелок ГМ-10 были установлены горелки BGEC 1000 фирмы Ray International (Германия) в комплекте с автоматикой АСУ ТП Nordvision, собственной разработки проектировщика. Управление агрегатами котла выведено в диспетчерскую.

Реконструкция позволила:

- реализовать программу полностью автоматической работы котла, в том числе режим пуска котла из холодного состояния до рабочих параметров и автоматический переход с основного топлива (газ) на резервное (печное топливо);

- выполнять работу горелок в диапазоне регулирования 1 : 10;

- обеспечить экономию средств заказчика за счёт сокращения энергопотребления и уменьшения обслуживающего персонала.

ООО «Норд Крафт» имеет большой опыт по модернизации газооборудования котлов ДКВР, ДЕ, ПТВМ, КВГМ как по отдельным проектам, так и в составе полной реконструкции котельной.

Замена «родных» горелок на котлах ДКВР на современные модулируемые, выпускаемые заводом «Старорусприбор», позволяет осуществить [2]:

- повышение КПД на 2,5-3,0 \%;

- увеличение диапазона регулирования до 1 : 10;

- возможность полной автоматизации котла;

- увеличение срока службы агрегата и межремонтного срока эксплуатации экранов топки;

- полное соответствие современным нормам экологии; 
- удобство обслуживания и эксплуатации;

- увеличение ресурса котла из-за плавного регулирования нагрузки.

В одной из котельных г. Пензы с тремя котлами ДКВР-6,5/13 проведена реконструкция котлов:

- два котла переведены на водогрейный режим работы с заменой горелок;

- один котёл оставлен в паровом режиме работы, но с возможностью понижения минимально допустимой нагрузки без замены горелок.

Энергоэкологическая эффективность модернизации газооборудования подтверждается данными таблиц 1 и 2.

Таблица 1. Режимная карта котла типа ДКВР-6,5/13, переведённого на водогрейный режим работы.

\begin{tabular}{|c|c|c|c|c|c|c|c|c|}
\hline \multicolumn{9}{|c|}{ Топливно-природный газ } \\
\hline \multirow{2}{*}{$\begin{array}{c}\text { № } \\
\Pi / \Pi\end{array}$} & \multirow{2}{*}{\multicolumn{3}{|c|}{ Наименование показателей }} & Единица & \multicolumn{4}{|c|}{ Тепловая нагрузка, \% } \\
\hline & & & & измерения & 67,9 & 92,4 & 111,4 & 122,3 \\
\hline 1 & \multicolumn{3}{|c|}{ Теплопроизводительность } & Гкал/ч & 2,5 & 3,4 & 4,1 & 4,5 \\
\hline 2 & \multicolumn{3}{|c|}{$\begin{array}{l}\text { Температура воды на входе в } \\
\text { котёл }\end{array}$} & ${ }^{\circ} \mathrm{C}$ & 60 & 60 & 61 & 62 \\
\hline 3 & \multicolumn{3}{|c|}{$\begin{array}{l}\text { Температура воды на выходе из } \\
\text { котла }\end{array}$} & ${ }^{\circ} \mathrm{C}$ & 77 & 84 & 90 & 94 \\
\hline 4 & \multicolumn{3}{|c|}{ Давление воды перед котлом } & МПа & 0,66 & 0,66 & 0,66 & 0,66 \\
\hline 5 & \multicolumn{3}{|c|}{ Давление воды за котлом } & МПа & 0,6 & 0,6 & 0,6 & 0,6 \\
\hline 6 & \multicolumn{3}{|c|}{ Расход воды через котёл } & $\mathrm{T} / \mathrm{Y}$ & 140 & 140 & 140 & 140 \\
\hline 7 & \multicolumn{3}{|c|}{ Давление газа перед горелками } & кПа & 10 & 20 & 30 & 100 \\
\hline 8 & \multicolumn{3}{|c|}{ Разрежение в топке } & Па & 20 & 24 & 26 & 30 \\
\hline \multirow{2}{*}{9} & \multirow{2}{*}{\multicolumn{2}{|c|}{$\begin{array}{l}\text { Содержание в } \\
\text { продуктах сгорания } \\
\text { за котлом: }\end{array}$}} & $\mathrm{CO}_{2}$ & $\%$ & 9,0 & 9,2 & 9,3 & 9,4 \\
\hline & & & $\mathrm{O}_{2}$ & $\%$ & 5,0 & 4,6 & 4,4 & 4,2 \\
\hline \multirow{4}{*}{10} & \multirow{4}{*}{\multicolumn{2}{|c|}{$\begin{array}{l}\text { Содержание в } \\
\text { продуктах сгорания } \\
\text { за экономайзером: }\end{array}$}} & $\mathrm{CO}_{2}$ & $\%$ & 8,0 & 8,3 & 8,4 & 8,5 \\
\hline & & & $\mathrm{O}_{2}$ & $\%$ & 6,8 & 6,3 & 6,1 & 5,9 \\
\hline & & & $N O_{x}$ & ppm & 112 & 125 & 133 & 145 \\
\hline & & & $N O_{x}^{\alpha=1}$ & $\mathrm{M \Gamma} / \mathrm{M}^{3}$ & 329 & 356 & 371 & 403 \\
\hline \multirow[b]{2}{*}{11} & \multirow{2}{*}{$\begin{array}{l}\text { Коэффициент } \\
\text { избытка } \\
\text { воздуха: }\end{array}$} & \multicolumn{2}{|c|}{ за котлом } & - & 1,31 & 1,28 & 1,27 & 1,25 \\
\hline & & \multicolumn{2}{|c|}{$\begin{array}{l}\text { за эконо- } \\
\text { майзером }\end{array}$} & - & 1,48 & 1,43 & 1,41 & 1,39 \\
\hline
\end{tabular}




\begin{tabular}{|c|c|c|c|c|c|c|c|}
\hline \multicolumn{8}{|c|}{ Топливно-природный газ } \\
\hline \multirow{2}{*}{$\begin{array}{l}\text { № } \\
\Pi / \Pi\end{array}$} & \multirow{2}{*}{\multicolumn{2}{|c|}{ Наименование показателей }} & \multirow{3}{*}{$\begin{array}{c}\text { Единица } \\
\text { измерения } \\
{ }^{\circ} \mathrm{C} \\
\end{array}$} & \multicolumn{4}{|c|}{ Тепловая нагрузка, \% } \\
\hline & & & & 67,9 & 92,4 & 111,4 & 122,3 \\
\hline \multirow[b]{2}{*}{12} & \multirow{2}{*}{$\begin{array}{l}\text { Температура } \\
\text { уходящих } \\
\text { газов: }\end{array}$} & за котлом & & 144 & 175 & 213 & 228 \\
\hline & & $\begin{array}{l}\text { за эконо- } \\
\text { майзером }\end{array}$ & ${ }^{\circ} \mathrm{C}$ & 108 & 128 & 151 & 158 \\
\hline 13 & \multicolumn{2}{|l|}{ Расход газа } & $\mathrm{M}^{3} / \mathrm{\varphi}$ & 342 & 465 & 564 & 623 \\
\hline 14 & \multicolumn{2}{|c|}{$\begin{array}{l}\text { Потеря тепла с уходящими } \\
\text { газами }\end{array}$} & $\%$ & 5,1 & 6,2 & 6,9 & 7,8 \\
\hline 15 & \multicolumn{2}{|c|}{$\begin{array}{l}\text { Потеря тепла в окружающую } \\
\text { среду }\end{array}$} & $\%$ & 3,4 & 2,4 & 2,2 & 1,9 \\
\hline 16 & \multicolumn{2}{|c|}{ КПД «брутто» } & $\%$ & 91,5 & 91,4 & 90,9 & 90,3 \\
\hline 17 & \multicolumn{2}{|c|}{$\begin{array}{l}\text { Удельный расход условного } \\
\text { топлива }\end{array}$} & $\frac{\text { кг у. т. }}{\text { Гкал }}$ & 156,1 & 156,3 & 157,2 & 158,2 \\
\hline 18 & \multicolumn{7}{|c|}{ На котле установлены 4 горелки ИГК-250 } \\
\hline
\end{tabular}

Таблица 2. Режимная карта котла типа ДКВР-6,5/13, переведённого на водогрейный режим работы.

\begin{tabular}{|c|c|c|c|c|c|c|c|}
\hline \multicolumn{8}{|c|}{ Топливно-природный газ } \\
\hline \multirow{2}{*}{$\begin{array}{l}\text { № } \\
\Pi / \Pi \\
\end{array}$} & \multirow{2}{*}{\multicolumn{2}{|c|}{ Наименование показателей }} & \multirow{2}{*}{$\begin{array}{c}\text { Единица } \\
\text { измерения }\end{array}$} & \multicolumn{4}{|c|}{ Тепловая нагрузка, \% } \\
\hline & & & & 48,9 & 62,5 & 84,2 & 103,3 \\
\hline 1 & \multicolumn{2}{|c|}{ Теплопроизво-дительность } & Гкал/ч & 1,8 & 2,3 & 3,1 & 3,8 \\
\hline 2 & \multicolumn{2}{|c|}{$\begin{array}{l}\text { Температура воды на входе в } \\
\text { котёл }\end{array}$} & ${ }^{\circ} \mathrm{C}$ & 60 & 60 & 60 & 61 \\
\hline 3 & \multicolumn{2}{|c|}{$\begin{array}{l}\text { Температура воды на выходе } \\
\text { из котла }\end{array}$} & ${ }^{\circ} \mathrm{C}$ & 73 & 77 & 82 & 88 \\
\hline 4 & \multicolumn{2}{|c|}{ Давление воды перед котлом } & МПа & 0,66 & 0,66 & 0,66 & 0,66 \\
\hline 5 & \multicolumn{2}{|c|}{ Давление воды за котлом } & МПа & 0,6 & 0,6 & 0,6 & 0,6 \\
\hline 6 & \multicolumn{2}{|c|}{ Расход воды через котёл } & $\mathrm{T} / \mathrm{Y}$ & 140 & 140 & 140 & 140 \\
\hline 7 & \multicolumn{2}{|l|}{$\begin{array}{l}\text { Давление газа перед } \\
\text { горелками }\end{array}$} & кПа & 10 & 10 & 10 & 10 \\
\hline 8 & \multicolumn{2}{|c|}{$\begin{array}{l}\text { Степень открытия газовой } \\
\text { заслонки }\end{array}$} & $\%$ & 21 & 25 & 30 & 35 \\
\hline 9 & \multicolumn{2}{|c|}{$\begin{array}{l}\text { Степень открытия воздушной } \\
\text { заслонки }\end{array}$} & $\%$ & 16 & 23 & 35 & 60 \\
\hline 10 & \multicolumn{2}{|l|}{ Разрежение в топке } & Па & $20-40$ & $20-40$ & $20-40$ & $20-40$ \\
\hline \multirow{4}{*}{11} & \multirow{4}{*}{$\begin{array}{l}\text { Содержание в } \\
\text { продуктах сгорания } \\
\text { за котлом: }\end{array}$} & $\mathrm{CO}_{2}$ & $\%$ & 8,9 & 9,1 & 9,3 & 9,6 \\
\hline & & $\mathrm{O}_{2}$ & $\%$ & 5,2 & 4,8 & 4,4 & 3,9 \\
\hline & & $N O_{x}$ & ppm & 24 & 27 & 28 & 29 \\
\hline & & $N O_{x}^{\alpha=1}$ & $\mathrm{M \Gamma} / \mathrm{M}^{3}$ & 64,5 & 70,6 & 71,4 & 71,6 \\
\hline
\end{tabular}




\begin{tabular}{|c|c|c|c|c|c|c|c|c|}
\hline \multicolumn{9}{|c|}{ Топливно-природный газ } \\
\hline \multirow{2}{*}{$\begin{array}{c}\text { № } \\
\text { П/П }\end{array}$} & \multirow{2}{*}{\multicolumn{3}{|c|}{ Наименование показателей }} & \multirow{2}{*}{$\begin{array}{c}\text { Единица } \\
\text { измерения }\end{array}$} & \multicolumn{4}{|c|}{ Тепловая нагрузка, \% } \\
\hline & & & & & 48,9 & 62,5 & 84,2 & 103,3 \\
\hline \multirow[b]{2}{*}{12} & \multirow{2}{*}{\multicolumn{2}{|c|}{$\begin{array}{l}\text { Содержание } \\
\text { в продуктах } \\
\text { сгорания } \\
\text { за экономайзером: }\end{array}$}} & $\mathrm{CO}_{2}$ & $\%$ & 8,6 & 8,8 & 9,0 & 9,3 \\
\hline & & & $\mathrm{O}_{2}$ & $\%$ & 5,7 & 5,3 & 5,0 & 4,4 \\
\hline \multirow{2}{*}{13} & \multirow{2}{*}{$\begin{array}{l}\text { Коэффициент } \\
\text { избытка } \\
\text { воздуха: }\end{array}$} & \multicolumn{2}{|c|}{ за котлом } & & 1,32 & 1,29 & 1,26 & 1,22 \\
\hline & & \multicolumn{2}{|c|}{$\begin{array}{l}\text { за эконо- } \\
\text { майзером }\end{array}$} & & 1,36 & 1,33 & 1,30 & 1,26 \\
\hline \multirow[b]{2}{*}{14} & \multirow{2}{*}{$\begin{array}{l}\text { Температура } \\
\text { уходящих } \\
\text { газов: }\end{array}$} & \multicolumn{2}{|c|}{ за котлом } & ${ }^{\circ} \mathrm{C}$ & 101 & 109 & 126 & 153 \\
\hline & & \multicolumn{2}{|c|}{$\begin{array}{l}\text { за эконо- } \\
\text { майзером }\end{array}$} & ${ }^{\circ} \mathrm{C}$ & 83 & 93 & 105 & 116 \\
\hline 15 & \multicolumn{3}{|l|}{ Расход газа } & $\mathrm{M}^{3} / \mathrm{\varphi}$ & 237 & 304 & 410 & 504 \\
\hline 16 & \multicolumn{3}{|c|}{$\begin{array}{l}\text { Потеря тепла с уходящими } \\
\text { газами }\end{array}$} & $\%$ & 3,3 & 3,8 & 4,3 & 4,8 \\
\hline 17 & \multicolumn{3}{|c|}{$\begin{array}{l}\text { Потеря тепла в окружающую } \\
\text { среду }\end{array}$} & $\%$ & 1,9 & 1,5 & 1,2 & 0,9 \\
\hline 18 & \multicolumn{3}{|l|}{ КПД «брутто» } & $\%$ & 94,8 & 94,7 & 94,5 & 94,3 \\
\hline 19 & \multicolumn{3}{|c|}{$\begin{array}{l}\text { Удельный расход условного } \\
\text { топлива }\end{array}$} & $\frac{\text { кг у. т. }}{\text { Гкал }}$ & 150,5 & 151,1 & 151,2 & 151,6 \\
\hline 20 & \multicolumn{8}{|c|}{ На котле установлены 2 горелки Weishaupt G9 1SF } \\
\hline
\end{tabular}

\section{Вывод}

В связи с тем, что существующие горелки на коммунальных паровых и водогрейных котлах не обеспечивают требования по энергоэффективности, охране окружающей среды, автоматизации и надёжности работы, в последние годы наметилась тенденция по их замене на современные.

Приведены результаты режимно-наладочных испытаний котла ДКВР-6,5/13, переведённого на водогрейный режим работы, до и после модернизации. Показана энергоэкологическая эффективность модернизации газооборудования. 


\section{Список используемых источников}

1. Прохоров С.Г. Модернизация водогрейных и паровых котлов малой мощности. Пенза: ПГУАС, 2015. 120 с.

2. Рекламные материалы компании «Рационал». URL: https://www.razional.ru (дата обращения: 08.02.2019).

3. Рекламные материалы компании «CIB UNIGAS». URL: http://cibunigasrus.ru (дата обращения: 12.02.2019).

4. Рекламные материалы OOO «Энергодевелопмент». URL: http://www.energodevelopment.ru (дата обращения: 02.02.2019).

5. Рекламные материалы ООО «Норд Крафт». URL: http://www.nordkraft.ru (дата обращения: 26.02.2019).

\section{References}

1. Prokhorov S.G. Modernizatsiya vodogreinykh i parovykh kotlov maloi moshchnosti [Modernization of Low-Power Water-Heating and Steam Boilers]. Penza: PSUAC, 2015. 120 p. [in Russian].

2. Reklamnye materialy kompanii «Ratsional» [Promotional materials of the company «Rational»]. Available at: https://www.razional.ru (accessed 08.02.2019). [in Russian].

3. Reklamnye materialy kompanii «CIB UNIGAS» [Promotional materials of the company «CIB UNIGAS»]. Available at: http://cibunigasrus.ru (accessed 12.02.2019). [in Russian].

4. Reklamnye materialy OOO «Energodevelopment» [Promotional materials «Energoteploremont»]. Available at: http://www.energodevelopment.ru (accessed 02.02.2019). [in Russian].

5. Reklamnye materialy OOO «Nord Kraft» [Promotional materials of «Nord Kraft»]. Available at: http://www.nordkraft.ru (accessed 26.02.2019). [in Russian]. 


\section{Сведения об авторах}

\section{About the authors}

Прохоров Сергей Григорьевич, канд. техн. наук, доцент кафедры «Теплогазоснабжение и вентиляция», ПГУАС, г. Пенза, Российская Федерация

Sergey G. Prokhorov, Candidate of Engineering Sciences, Assistant Professor of Heat and Gas Supply and Ventilation Department, PSUAC, Penza, Russian Federation

e-mail: tgv@pguas.ru

Назаров Илья Сергеевич, магистрант кафедры «Теплогазоснабжение и вентиляция», ПГУАС, г. Пенза, Российская Федерация

Ilya S. Nazarov, Undergraduate Student of Heat and Gas Supply and Ventilation Department, PSUAC, Penza, Russian Federation

e-mail: ilya.nazarov2011@yandex.ru 